
(RE\&PQJ)

\title{
Control Strategy of PWM Rectifiers Connected to Unbalanced Grids
}

\author{
Martin Bejvl $1^{+}$, Jan Švec*, Josef Tlustý, and Viktor Valouch* \\ *Department of Electric Power Engineering \\ Faculty of Electrical Engineering, CTU \\ Prague, Czech Republic \\ Email: valouch@it.cas.cz \\ ${ }^{+}$Institute of Thermomechanics \\ Academy of Sciences of the Czech Republic \\ Prague, Czech Republic \\ Email: bejvl@it.cas.cz
}

\begin{abstract}
Current-controlled voltage source converters are widely used in grid-connected applications, for example at ac drives with indirect frequency converters. The negative sequence component of the grid voltage causes ripples of the dc voltage in the intermediate circuit. Some sophisticated topologies of current controllers that can cope with grids containing both the positive and negative sequence components are summarized and compared for this purpose. A new dual current control algorithm was developed and tested in the Matlab/Simulink environment.
\end{abstract}

\section{Key words}

Electric power system, PWM rectifier, dc voltage ripple, dual current controller, simulation

\section{Introduction}

The ac/dc rectifiers are often used in many applications, especially in electric drives with ac motors and generators. The rectifier works at these drives as an input part of the indirect frequency inverter.

In ideal situation, the 3-phase grid voltage is harmonic, shifted by $120^{\circ}$ phase-by-phase, voltage and current are in phase. The track of the space vector of the 3-phase voltage transformed to $\alpha \beta$ coordinates has a form of the circle.

In real situation, the 3-phase grid voltage is distorted by high-order harmonics and by a negative sequence component, producing ripples in the voltage on the capacitors in the intermediate circuit. The 3-phase ac current is disturbed as well.

Thus, there is a demand to develop such a control strategy of the ac/dc rectifier that can cope with grid voltage disturbances, among them high-order harmonics and the negative sequence component mainly belong.

\section{Review of Main Control Methods}

The object of the work is an analysis of the control of the positive and negative sequence of the ac current of a PWM rectifier in order to eliminate reactive power, highorder harmonics of the grid current and ripples of the voltage in the dc intermediate circuit.

Both sequences of the grid current are controlled separately and simultaneously. The positive sequence of the current is controlled in the positive coordinates, which looks like dc control. The negative sequence of the current is controlled in the negative coordinates, which looks like dc control too. Both the controls are realized by separate PI controllers working simultaneously.

Fig. 1 displays a basic scheme of the PWM rectifier. The system consists of three parts: line filter, rectifying bridge, and intermediate dc circuit. L-filters, which consist of separate inductors, are the most often used line filters. The purpose of the line filter is to smooth the current ripple produced by PWM switching.

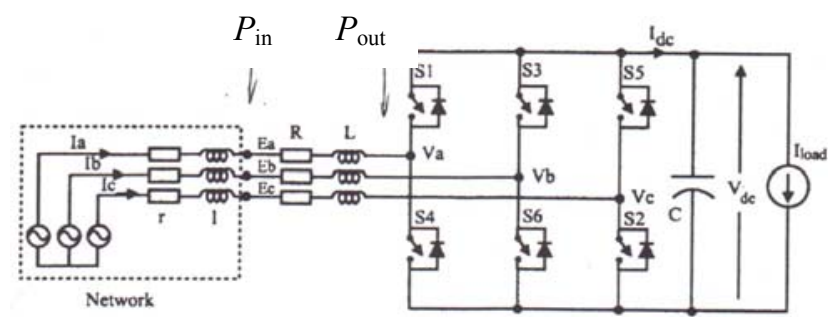

Fig. 1. Scheme of a PWM rectifier as a voltage source; reproduced from [1]

The standard dual current controller [1], [2] is based on calculating the reference grid currents $i_{\mathrm{dq}}^{\mathrm{p} *} i_{\mathrm{dq}}^{\mathrm{n} *}$ with help of the grid voltages $e_{\mathrm{a}}, e_{\mathrm{b}}, e_{\mathrm{c}}$ (at "in" side of the 
reactor L). For an exactly working control system it is necessary to compute the current references from the voltages $v_{\mathrm{a}}, v_{\mathrm{b}}, v_{\mathrm{c}}$ (at "out" side of the reactor $\mathrm{L}$ ), thus from the voltages at the ac poles of the converter, because $v_{\mathrm{a}}, v_{\mathrm{b}}, v_{\mathrm{c}}$, together with phase currents, are responsible for an active power that can cause dc voltage ripples. It means that the control system based on the grid voltages $e_{\mathrm{a}}, e_{\mathrm{b}}, e_{\mathrm{c}}$ is not usable for extremely unbalanced grid.

A method, which calculates the current references $i_{\mathrm{dq}}^{\mathrm{p} *}$, $i_{\mathrm{dq}}^{\mathrm{n} *}$ with help of the converter voltage $v_{\mathrm{dq}}^{\mathrm{pn}}$, was proposed in [3]. The converter voltages $v_{\mathrm{dq}}^{\mathrm{pn}}$ are expressed by $v_{\mathrm{dq}}^{\mathrm{pn}}=e_{\mathrm{dq}}^{\mathrm{pn}} \pm \omega L i_{\mathrm{qd}}^{\mathrm{pn}}$, where $e_{\mathrm{dq}}^{\mathrm{pn}}$ are measured. The backward of this method consists in necessity to solve nonlinear equations, which is very difficult and complicated.

In [4] the method was presented that avoids the nonlinearity. The nonlinearity is transformed to a linearity by using an additional feedback path for pole voltages $\left(v_{\mathrm{a}}, v_{\mathrm{b}}, v_{\mathrm{c}}\right)$. So, the algorithm for calculating the current reference becomes simpler. The four sequence components of the pole voltages $v_{\mathrm{d}}^{\mathrm{p}}, v_{\mathrm{q}}^{\mathrm{p}}, v_{\mathrm{d}}^{\mathrm{n}}, v_{\mathrm{q}}^{\mathrm{n}}$ are extracted from the space vector PWM block and fed back to the algorithm for calculating the current references. A disadvantage of this method is that oscillating powers, which are dissipated in the input filtering inductors, are neglected.

The method [5] comes from calculating power, which is dissipated in the input inductors. The method calculates the current references with the help of the measured grid voltage $e$. The difference is set between the power at the grid and at the ac side of the converter. So, the regard to losses at the inductors is taken. But the equations for the power are still nonlinear.
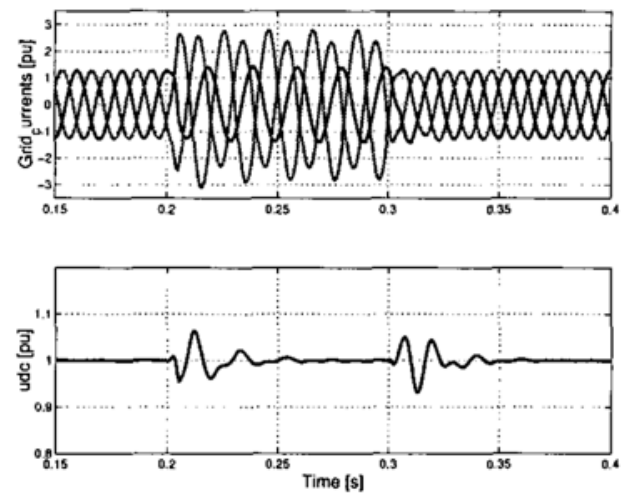

Fig. 2. Grid current (top) and de voltage (bottom) in case of a two-phase voltage dip with dual current controller when oscillating power flows from grid into filter [5]

The authors avoided the nonlinearity by giving the previous patterns of the calculated reference currents to the equations for calculating the actual current references. Two different methods for calculating power, which is dissipated in the inductor filters, may be used:
1) In the first case the dc side of the converter supplies the oscillating power to the filter, which means that the oscillating power is set to zero on the grid side, i.e. $P_{\mathrm{s} 2}^{\text {in }}=P_{\mathrm{c} 2}^{\text {in }}=0$;

2 ) In the second case the oscillating power flows from the grid into the filter, i.e. the oscillating power is forced to zero at the converter terminals $P_{\mathrm{c} 2}^{\mathrm{in}}=-\Delta P_{\mathrm{c} 2}$ and $P_{s 2}^{\mathrm{in}}=-$ $\Delta P_{\mathrm{s} 2}$.

The grid phase currents and dc voltage in case of a two- phase voltage dip with such a dual current controller, when oscillating power flows from grid into filter, are presented in Fig. 2.

In [6] the current references are calculated on the basis on the measured grid voltages $e$, from which the converter terminal voltages are calculated using the inductance of the grid filter and currents in the previous instant. Thus, the current references are computed from the estimated voltages $v_{\mathrm{a}}, v_{\mathrm{b}}, v_{\mathrm{c}}$ (at "out" side of the reactor L). Nevertheless, the resistance of the inductor is neglected, like that in [3], [4].

In [7], [8] the current references were calculated from the grid voltages $e_{\mathrm{a}}, e_{\mathrm{b}}, e_{\mathrm{c}}$ (at "in" side of the reactor $\mathrm{L}$ ), so the same restriction is laid on the method like that in [2].

A similar strategy like that proposed in [5], method 2) is presented in [9]. The current components calculation respects the dynamics and power losses in the grid filter by adding additional terms to the values of the reference currents calculated on the assumptions $R=0$.

\section{Proposed Strategy of Current Reference Calculation}

The unbalanced three phase grid voltage at the input of the rectifier $\left(e_{\mathrm{a}}, e_{\mathrm{b}}, e_{\mathrm{c}}\right)$ may be expressed in the static $\alpha \beta$ coordinates by the superposition of the positive and negative symmetrical sequence by the equation (1)

$$
\bar{e}_{\mathrm{dqs}}=\frac{2}{3}\left[e_{\mathrm{a}}+e_{\mathrm{b}} \mathrm{e}^{\mathrm{j} 2 \pi / 3}+e_{\mathrm{c}} \mathrm{e}^{-\mathrm{j} 2 \pi / 3}\right]=\mathrm{e}^{\mathrm{j} \omega t} \bar{e}_{\mathrm{dq}}^{\mathrm{p}}+\mathrm{e}^{-\mathrm{j} \omega t} \bar{e}_{\mathrm{dq}}^{\mathrm{n}}
$$

where $\bar{e}_{\mathrm{dq}}^{\mathrm{p}}=e_{\mathrm{d}}^{\mathrm{p}}+\mathrm{j} e_{\mathrm{q}}^{\mathrm{p}}, \bar{e}_{\mathrm{dq}}^{\mathrm{n}}=e_{\mathrm{d}}^{\mathrm{n}}+\mathrm{j} e_{\mathrm{q}}^{\mathrm{n}}$ are the positive and negative voltage symmetrical components expressed in the positive, negative synchronous reference frames, respectively, and $\omega$ is the angular frequency. Thus, the term $\mathrm{e}^{\mathrm{j} \omega t} \bar{e}_{\mathrm{dq}}^{\mathrm{p}}$ expresses the positive sequence, which rotates counter-clockwise, while the term $e^{-\mathrm{j} \omega t} \bar{e}_{\mathrm{dq}}^{\mathrm{n}}$ expresses the negative sequence, which rotates clockwise.

The voltage equation is given by

$$
\bar{e}_{\mathrm{dqs}}=\bar{v}_{\mathrm{dqs}}+L \frac{\mathrm{d} \bar{i}_{\mathrm{dqs}}}{\mathrm{dt}}+R \bar{i}_{\mathrm{dqs}}
$$

and after the separation into the negative and positive components and respective $\mathrm{d}, \mathrm{q}$ transformations 


$$
\begin{aligned}
& e_{\mathrm{d}}^{\mathrm{p}}=v_{\mathrm{d}}^{\mathrm{p}}+L \frac{\mathrm{d} i_{\mathrm{d}}^{\mathrm{p}}}{\mathrm{dt}}+R i_{\mathrm{d}}^{\mathrm{p}}-\omega L i_{\mathrm{q}}^{\mathrm{p}} \\
& e_{\mathrm{q}}^{\mathrm{p}}=v_{\mathrm{q}}^{\mathrm{p}}+L \frac{\mathrm{d} i_{\mathrm{q}}^{\mathrm{p}}}{\mathrm{dt}}+R i_{\mathrm{q}}^{\mathrm{p}}+\omega L i_{\mathrm{d}}^{\mathrm{p}} \\
& e_{\mathrm{d}}^{\mathrm{n}}=v_{\mathrm{d}}^{\mathrm{n}}+L \frac{\mathrm{d} i_{\mathrm{d}}^{\mathrm{n}}}{\mathrm{dt}}+R i_{\mathrm{d}}^{\mathrm{n}}+\omega L i_{\mathrm{q}}^{\mathrm{n}} \\
& e_{\mathrm{q}}^{\mathrm{n}}=v_{\mathrm{q}}^{\mathrm{n}}+L \frac{\mathrm{d} i_{\mathrm{q}}^{\mathrm{n}}}{\mathrm{dt}}+R i_{\mathrm{q}}^{\mathrm{n}}-\omega L i_{\mathrm{d}}^{\mathrm{n}}
\end{aligned}
$$

If we assume the unbalanced input voltage, the apparent power at the side of the grid ("in" side of the rector $\mathrm{L}$ ) is expressed

$$
S^{\mathrm{in}}=3 / 2 \bar{e}_{\mathrm{dq}} \overline{\bar{i}}_{\mathrm{dq}}^{*}=3 / 2\left(\mathrm{e}^{\mathrm{j} \omega t} \bar{e}_{\mathrm{dq}}^{\mathrm{p}}+\mathrm{e}^{-\mathrm{j} \omega t} \bar{e}_{\mathrm{dq}}^{\mathrm{n}}\right)\left(\mathrm{e}^{\mathrm{j} \omega t} \bar{i}_{\mathrm{dq}}^{\mathrm{p}}+\mathrm{e}^{-\mathrm{j} \omega t} \bar{i}_{\mathrm{dq}}^{\mathrm{n}}\right)^{*}
$$

and a similar expression we get for the power at converter terminals ("out" side of the inductor $\mathrm{L}$ ).

$$
\begin{aligned}
& \text { Regarding } S^{\text {in/out }}=P^{\text {in/out }}+\mathrm{j} Q^{\text {in/out }} \text { we obtain } \\
& P^{\text {in/out }}(\mathrm{t})=P_{0}^{\text {in/out }}+P_{\mathrm{c} 2}^{\text {in/out }} \cos (2 \omega t)+P_{\mathrm{s} 2}^{\text {in/out }} \sin (2 \omega t) \\
& Q^{\text {in/out }}(\mathrm{t})=Q_{0}^{\text {in/out }}+Q_{\mathrm{c} 2}^{\text {in/out }} \cos (2 \omega t)+Q_{\mathrm{s} 2}^{\text {in/out }} \sin (2 \omega t)
\end{aligned}
$$

If the coefficients $P_{\mathrm{c} 2}^{\mathrm{in} / \mathrm{out}}, P_{\mathrm{s} 2}^{\mathrm{in} / \text { out }}, Q_{\mathrm{c} 2}^{\text {in/out }}$ and $Q_{\mathrm{s} 2}^{\text {in/out }}$ are not equal to zero, then dc voltage $V_{\mathrm{dc}}$ shows $100 \mathrm{~Hz}$ ripple. Thus, the PWM rectifier must be controlled so that the coefficients $P_{\mathrm{c} 2}^{\text {in/out }}, P_{\mathrm{s} 2}^{\text {in } / \mathrm{out}}, Q_{\mathrm{c} 2}^{\text {in/out }}$ and $Q_{\mathrm{s} 2}^{\text {in/out }}$ are driven to be zero. It is also important to drive the coefficient $Q_{0}^{\text {in/out }}$ to be zero in order to obtain unity power factor.

The power components can be expressed in a matrix form (here for "in" side of the inductor)

$$
\frac{2}{3}\left[\begin{array}{c}
P_{0}^{\text {in }} \\
Q_{0}^{\text {in }} \\
P_{\mathrm{s} 2}^{\text {in }} \\
P_{\mathrm{c} 2}^{\text {in }}
\end{array}\right]=\left[\begin{array}{cccc}
e_{\mathrm{d}}^{\mathrm{p}} & e_{\mathrm{q}}^{\mathrm{p}} & e_{\mathrm{d}}^{\mathrm{n}} & e_{\mathrm{q}}^{\mathrm{n}} \\
e_{\mathrm{q}}^{\mathrm{p}} & -e_{\mathrm{d}}^{\mathrm{p}} & e_{\mathrm{q}}^{\mathrm{n}} & -e_{\mathrm{d}}^{\mathrm{n}} \\
e_{\mathrm{q}}^{\mathrm{n}} & -e_{\mathrm{d}}^{\mathrm{n}} & -e_{\mathrm{q}}^{\mathrm{p}} & e_{\mathrm{d}}^{\mathrm{p}} \\
e_{\mathrm{d}}^{\mathrm{n}} & e_{\mathrm{q}}^{\mathrm{n}} & e_{\mathrm{d}}^{\mathrm{p}} & e_{\mathrm{q}}^{\mathrm{p}}
\end{array}\right]\left[\begin{array}{c}
i_{\mathrm{d}}^{\mathrm{p}}(t) \\
i_{\mathrm{q}}^{\mathrm{p}}(t) \\
i_{\mathrm{d}}^{\mathrm{n}}(t) \\
i_{\mathrm{q}}^{\mathrm{n}}(t)
\end{array}\right]
$$

Similarly, we can express the matrix equation for "out" side of the inductor $L$ (for the converter output voltage $v$ )

$$
\frac{2}{3}\left[\begin{array}{c}
P_{0}^{\text {out }} \\
Q_{0}^{\text {out }} \\
P_{\mathrm{s} 2}^{\text {out }} \\
P_{\mathrm{c} 2}^{\text {out }}
\end{array}\right]=\left[\begin{array}{cccc}
v_{\mathrm{d}}^{\mathrm{p}} & v_{\mathrm{q}}^{\mathrm{p}} & v_{\mathrm{d}}^{\mathrm{n}} & v_{\mathrm{q}}^{\mathrm{n}} \\
v_{\mathrm{q}}^{\mathrm{p}} & -v_{\mathrm{d}}^{\mathrm{p}} & v_{\mathrm{q}}^{\mathrm{n}} & -v_{\mathrm{d}}^{\mathrm{n}} \\
v_{\mathrm{q}}^{\mathrm{n}} & -v_{\mathrm{d}}^{\mathrm{n}} & -v_{\mathrm{q}}^{\mathrm{p}} & v_{\mathrm{d}}^{\mathrm{p}} \\
v_{\mathrm{d}}^{\mathrm{n}} & v_{\mathrm{q}}^{\mathrm{n}} & v_{\mathrm{d}}^{\mathrm{p}} & v_{\mathrm{q}}^{\mathrm{p}}
\end{array}\right]\left[\begin{array}{c}
i_{\mathrm{d}}^{\mathrm{p}}(t) \\
i_{\mathrm{q}}^{\mathrm{p}}(t) \\
i_{\mathrm{d}}^{\mathrm{n}}(t) \\
i_{\mathrm{q}}^{\mathrm{n}}(t)
\end{array}\right]
$$

If we want to obtain zero reactive power and the constant dc voltage $v_{\mathrm{dc}}$, supposing that inverter losses are neglected, we must set

$$
\frac{2}{3}\left[P_{0}^{\text {out }} Q_{0}^{\text {out }} P_{\mathrm{s} 2}^{\text {out }} P_{\mathrm{c} 2}^{\text {out }}\right]^{T}=\frac{2}{3}\left[P_{0}^{\text {out }} 000\right]^{T}
$$

by generating an appropriate set of the current components $i_{\mathrm{d}}^{\mathrm{p}}, i_{\mathrm{q}}^{\mathrm{p}}, i_{\mathrm{d}}{ }^{\mathrm{n}}, i_{\mathrm{q}}{ }^{\mathrm{n}}$ with regard to the voltage components $v_{\mathrm{d}}{ }^{\mathrm{p}}, v_{\mathrm{q}}^{\mathrm{p}}, v_{\mathrm{d}}{ }^{\mathrm{n}}, v_{\mathrm{q}}{ }^{\mathrm{n}}$.

We have proposed a new simplified method to calculate the reference currents for the dual current controller. According to (10) and the demand

$$
\frac{2}{3}\left[P_{0}^{\text {out }} Q_{0}^{\text {out }} P_{\mathrm{s} 2}^{\text {out }} P_{\mathrm{c} 2}^{\text {out }}\right]^{T}=\frac{2}{3}\left[P_{0}^{\text {out }} 000\right]^{T}
$$

we can write

$$
\left[\begin{array}{c}
i_{\mathrm{d}}^{\mathrm{p}}(t) \\
i_{\mathrm{q}}^{\mathrm{p}}(t) \\
i_{\mathrm{d}}^{\mathrm{n}}(t) \\
i_{\mathrm{q}}^{\mathrm{n}}(t)
\end{array}\right]=\left[\begin{array}{cccc}
v_{\mathrm{d}}^{\mathrm{p}} & v_{\mathrm{q}}^{\mathrm{p}} & v_{\mathrm{d}}^{\mathrm{n}} & v_{\mathrm{q}}^{\mathrm{n}} \\
v_{\mathrm{q}}^{\mathrm{p}} & -v_{\mathrm{d}}^{\mathrm{p}} & v_{\mathrm{q}}^{\mathrm{n}} & -v_{\mathrm{d}}^{\mathrm{n}} \\
v_{\mathrm{q}}^{\mathrm{n}} & -v_{\mathrm{d}}^{\mathrm{n}} & -v_{\mathrm{q}}^{\mathrm{p}} & v_{\mathrm{d}}^{\mathrm{p}} \\
v_{\mathrm{d}}^{\mathrm{n}} & v_{\mathrm{q}}^{\mathrm{n}} & v_{\mathrm{d}}^{\mathrm{p}} & v_{\mathrm{q}}^{\mathrm{p}}
\end{array}\right]^{-1}\left[\begin{array}{c}
\frac{2}{3} P_{0}^{\text {out }} \\
0 \\
0 \\
0
\end{array}\right]=
$$

$$
=\frac{2 P_{0}^{\text {out }}}{3 D}\left[\begin{array}{c}
v_{\mathrm{d}}^{\mathrm{p}} \\
v_{\mathrm{q}}^{\mathrm{p}} \\
-v_{\mathrm{d}}^{\mathrm{n}} \\
-v_{\mathrm{q}}^{\mathrm{n}}
\end{array}\right]=Y_{0}^{\text {out }}\left(e_{\mathrm{d}}^{\mathrm{p}}, e_{\mathrm{q}}^{\mathrm{p}}, e_{\mathrm{d}}^{\mathrm{n}}, e_{\mathrm{q}}^{\mathrm{n}}, P_{0}^{\text {out }}\right)\left[\begin{array}{c}
v_{\mathrm{d}}^{\mathrm{p}} \\
v_{\mathrm{q}}^{\mathrm{p}} \\
-v_{\mathrm{d}}^{\mathrm{n}} \\
-v_{\mathrm{q}}^{\mathrm{n}}
\end{array}\right]
$$

where $Y_{0}^{\text {out }}\left(e_{\mathrm{d}}^{\mathrm{p}}, e_{\mathrm{q}}^{\mathrm{p}}, e_{\mathrm{d}}^{\mathrm{n}}, e_{\mathrm{q}}^{\mathrm{n}}, P_{0}^{\text {out }}\right)$ is a function of the measured grid voltages and the active power at the terminals of the converter, which is the output signal of the dc voltage controller. If the resistance $R$ of the input filter is neglected, the determinant $D$ may be calculated as

$$
\left.D=\left[u^{\mathrm{pn}}+\sqrt{\left(u^{\mathrm{pn}^{2}}-u_{\mathrm{L}}^{2}\right.}\right)\right] / 2
$$

where

$$
\begin{aligned}
u^{\mathrm{pn}}=e^{\mathrm{p}^{2}}-e^{\mathrm{n}{ }^{2}} & , u_{\mathrm{L}}=4 \omega L P_{0}^{\text {out }} / 3 \\
e^{\mathrm{p}^{2}}=e_{\mathrm{d}}^{\mathrm{p}^{2}}+e_{\mathrm{q}}^{\mathrm{p}^{2}} & e^{\mathrm{n}^{2}}=e_{\mathrm{d}}^{\mathrm{n}^{2}}+e_{\mathrm{q}}^{\mathrm{n}^{2}}
\end{aligned}
$$

and the converter terminal voltages are calculated on the basis of the measured grid voltages

$$
\begin{aligned}
v_{\mathrm{d}}^{\mathrm{p}} & =\left(e_{\mathrm{d}}^{\mathrm{p}}+K e_{\mathrm{q}}^{\mathrm{p}}\right) / D^{\mathrm{pn}} \\
v_{\mathrm{q}}^{\mathrm{p}} & =\left(e_{\mathrm{q}}^{\mathrm{p}}-K e_{\mathrm{d}}^{\mathrm{p}}\right) / D^{\mathrm{pn}} \\
v_{\mathrm{d}}^{\mathrm{n}} & =\left(e_{\mathrm{d}}^{\mathrm{n}}+K e_{\mathrm{q}}^{\mathrm{n}}\right) / D^{\mathrm{pn}} \\
v_{\mathrm{q}}^{\mathrm{n}} & =\left(e_{\mathrm{q}}^{\mathrm{n}}-K e_{\mathrm{d}}^{\mathrm{n}}\right) / D^{\mathrm{pn}}
\end{aligned}
$$


where

$$
K=\omega L Y_{0}^{\text {out }}, \quad D^{\mathrm{pn}}=1+K^{2}
$$

It is obvious that the calculation of the reference converter currents for the dual current controller based on the measured and control variables does need neither the solution of the set of nonlinear equations nor using the previous patterns of the calculated reference current in (12)-(17).

The resistance $R$ of the input filter and its dynamic behavior has been neglected in (12)-(17). To avoid a solution of a system of non-linear equations we can respect the losses produced in the line inductor by modifying the value $P_{0}^{\text {out }}$, which is produced as the output of the dc voltage controller. The losses calculated iteratively from the currents $\left(i_{\mathrm{d}}^{\mathrm{p}}, i_{\mathrm{q}}^{\mathrm{p}}, i_{\mathrm{d}}^{\mathrm{n}}, i_{\mathrm{q}}^{\mathrm{n}}\right)$ in the previous instant provide us with such a correcting term $P_{\text {loss } 0}$ that may be added to the output $P_{0}^{\text {out }}$ of the voltage controller.

The voltage drops on the line inductor for positive and negative components in steady states are

$$
\begin{aligned}
& \bar{e}_{\mathrm{dq}}^{\mathrm{p}}-\bar{v}_{\mathrm{dq}}^{\mathrm{p}}=R \bar{i}_{\mathrm{dq}}^{\mathrm{p}}+\mathrm{j} \omega L{\overline{i_{\mathrm{dq}}}}^{\mathrm{p}} \\
& \bar{e}_{\mathrm{dq}}^{\mathrm{n}}-\bar{v}_{\mathrm{dq}}^{\mathrm{n}}=R \bar{i}_{\mathrm{dq}}^{\mathrm{n}}-\mathrm{j} \omega L{\overline{i_{\mathrm{dq}}}}^{\mathrm{n}}
\end{aligned}
$$

and the respective active power

$$
\left.P_{\text {loss }}=3 / 2 \operatorname{Re}\left\{\begin{array}{l}
{\left[R\left({\overline{i_{\mathrm{dq}}}}^{\mathrm{p}}+\mathrm{e}^{-\mathrm{j} 2 \omega t}{\overline{i_{\mathrm{dq}}^{\mathrm{n}}}}^{\mathrm{n}}\right)+\right.} \\
\left.\mathrm{j} \omega L\left({\overline{i_{\mathrm{dq}}}}^{\mathrm{p}}-\mathrm{e}^{-\mathrm{j} 2 \omega t}{\overline{i_{\mathrm{dq}}}}^{\mathrm{n}}\right)\right]\left(\bar{i}_{\mathrm{dq}}^{\mathrm{p}}+\mathrm{e}^{-\mathrm{j} 2 \omega t}{\overline{i_{\mathrm{dq}}}}^{\mathrm{n}}\right.
\end{array}\right)^{*}\right\}
$$

After performing that we get

$$
P_{\text {loss }}=P_{\text {loss } 0}+P_{\text {lossc } 2}+P_{\text {losss } 2}
$$

where

$$
\begin{aligned}
& P_{\text {loss } 0}=3 / 2 R\left(i_{\mathrm{d}}^{\mathrm{p}^{2}}+i_{\mathrm{q}}^{\mathrm{p}^{2}}+i_{\mathrm{d}}^{\mathrm{n}^{2}}+i_{\mathrm{q}}^{\mathrm{n}^{2}}\right) \\
& P_{\text {lossc } 2}=3\left[R\left(i_{\mathrm{d}}^{\mathrm{p}} i_{\mathrm{d}}^{\mathrm{n}}+i_{\mathrm{q}}^{\mathrm{p}} i_{\mathrm{q}}^{\mathrm{n}}\right)+\omega L\left(i_{\mathrm{d}}^{\mathrm{p}} i_{\mathrm{q}}^{\mathrm{n}}-i_{\mathrm{q}}^{\mathrm{p}} i_{\mathrm{d}}^{\mathrm{n}}\right)\right] \cos (2 \omega t) \\
& P_{\text {losss } 2}=3\left[R\left(i_{\mathrm{d}}^{\mathrm{p}} i_{\mathrm{q}}^{\mathrm{n}}-i_{\mathrm{q}}^{\mathrm{p}} i_{\mathrm{d}}^{\mathrm{n}}\right)-\omega L\left(i_{\mathrm{d}}^{\mathrm{p}} i_{\mathrm{d}}^{\mathrm{n}}+i_{\mathrm{q}}^{\mathrm{p}} i_{\mathrm{q}}^{\mathrm{n}}\right)\right] \sin (2 \omega t)
\end{aligned}
$$

To respect the terms $P_{\text {lossc2 }}, P_{\text {losss } 2}$ in the calculation of the reference grid currents $i_{\mathrm{d}}{ }^{\mathrm{p}}, i_{\mathrm{q}}{ }^{\mathrm{p}}, i_{\mathrm{d}}{ }^{\mathrm{n}}, i_{\mathrm{q}}{ }^{\mathrm{n}}$ exactly, the respective two zeros in the right-hand side of (11) should be replaced by the magnitudes of these two terms. It would result in additional components in the reference grid currents $i_{\mathrm{d}}{ }^{\mathrm{p}}, i_{\mathrm{q}}{ }^{\mathrm{p}}, i_{\mathrm{d}}{ }^{\mathrm{n}}, i_{\mathrm{q}}{ }^{\mathrm{n}}$ calculated by using (12). It was recognized by simulations that the effect of that is negligible for usual values $\mathrm{R}, \mathrm{L}$ of the line inductor. Thus, the losses produced in the line inductor were respected with a sufficient precision only by the correcting term $P_{\text {loss } 0}$ as explained before.

\section{Verification of Proposed Strategy}

Figs. 3-6 show the results of the simulation of the proposed algorithm in the Matlab/Simulink environment. The grid voltage contains the positive symmetrical component ( 1 in the p.u. system), negative symmetrical component $(0.5$ p.u. $), 5^{\text {th }}$ harmonic $(0.2$ p.u. $)$, and its magnitude is modulated by the subharmonic signal $(0.2$ p.u.) with the frequency $5 \mathrm{~Hz}$. The converter switching frequency was $2400 \mathrm{~Hz}$, and the inductance $L=0.1$ p.u. with $R=0.02$ p.u. In the instant $0.3 \mathrm{~s}$ the reference dc voltage was increased by $10 \%$, in $0.5 \mathrm{~s}$ the power consumed from the dc capacitor was increased from zero to the value 0.3 p.u. In the time interval $<0.7,0.8>\mathrm{s}$ the voltage drop from 1 p.u. to 0.1 p.u. in the phase $a$ was applied. The grid voltage components $e_{\mathrm{d}}^{\mathrm{p}}, e_{\mathrm{q}}^{\mathrm{p}}, e_{\mathrm{d}}^{\mathrm{n}}, e_{\mathrm{q}}^{\mathrm{n}}$ in (13)-(16) were calculated by the CDSC based PLL circuitry presented in [10].

Fig. 3 shows the waveforms of the demanded and actual dc voltage, the load power withdrawn from the dc side of the PWM rectifier and the output $P_{0}^{\text {out }}$ of the dc voltage controller that enters the algorithm (12)-(21).

The currents $\left(i_{\mathrm{d}}^{\mathrm{p}}, i_{\mathrm{q}}^{\mathrm{p}}, i_{\mathrm{d}}^{\mathrm{n}}, i_{\mathrm{q}}^{\mathrm{n}}\right)$, Fig. 4 , are the reference current components calculated by using (12).

Fig. 5 shows the detail of the dc voltage waveform in the time interval $\langle 0.5,1\rangle$ from Fig. 3. There are no fluctuations in the dc voltage in steady states, which would result from the occurrence of the huge negative symmetrical component ( 0.5 p.u.) and other detrimental components in the grid voltage if only a single current controller was used.

It is clear from Fig. 6 that the unwanted dc reactive power component $\mathrm{qdc}=Q_{0}^{\text {out }}$ as well as fluctuating active power components $[\mathrm{ps} \mathrm{pc}]=\left[P_{\mathrm{s} 2}^{\text {out }} P_{\mathrm{c} 2}^{\text {out }}\right]$ are near to zero in steady states in accordance with the demand (11), while the active power component pdc follows the power $p_{\mathrm{L}}$ (presented in Fig. 3) consumed from the dc capacitor.

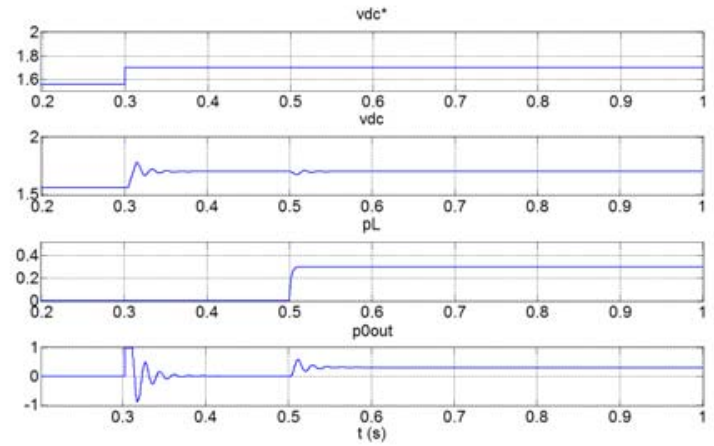

Fig. 3. Results of simulation of proposed algorithm (12)(21): dc voltage, load power and output of dc voltage controller (p.u.) 


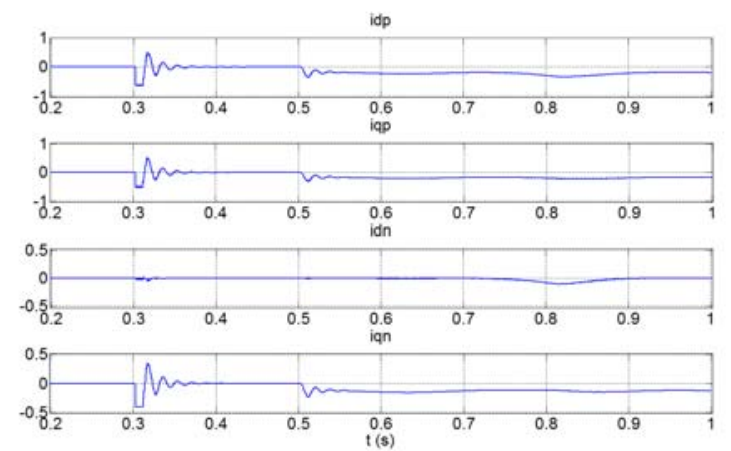

Fig. 4. Results of simulation of proposed algorithm (12)(21): reference current components (p.u.)

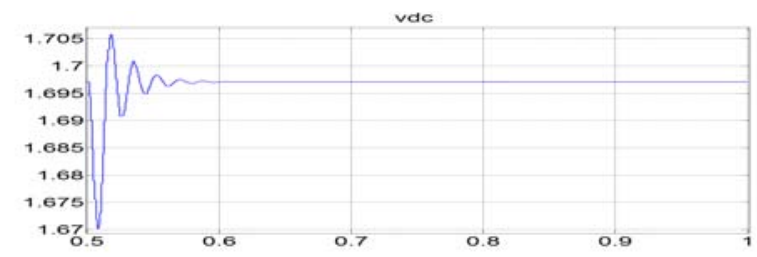

Fig.5. Results of simulation of proposed algorithm (12)(21): detail of de voltage from Fig. 3 in time interval $<0.5$, $1>$

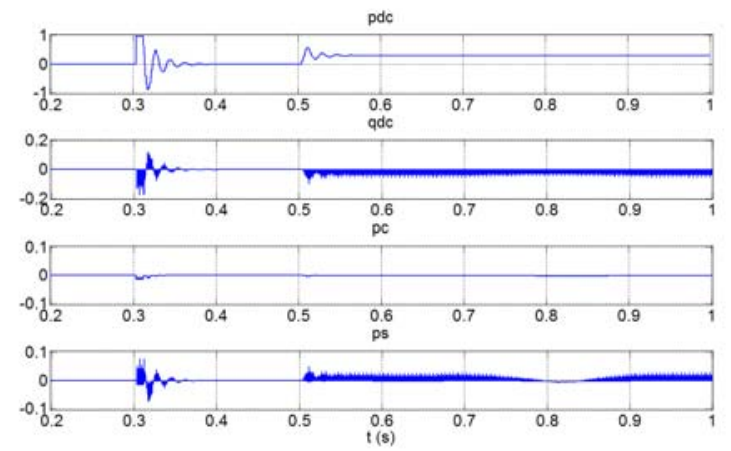

Fig.6. Results of simulation of proposed algorithm (12)(21): active and reactive power components at ac side of converter (p.u.)

\section{Conclusion}

An unbalanced and disturbed input voltage causes a wrong function of grid connected inverters in terms of the grid currents disturbances and the ripples of the dc voltage. Thus, different strategies of the compensation of these disturbances must be tested in different non-standard states and also in transient processes.

A lot of effort has been made to analyze and compare many published control schemes that aspire to compensate the input voltage unbalance reliably. A new simple dual current control algorithm was developed and tested in the Matlab/Simulink environment with good results.

\section{Acknowledgement}

The financial supports of the Institute of Thermomechanics (project RVO//:61388998) and Faculty of Electrical Engineering, CTU (project SGS12/139/OHK3/2T/13) are highly acknowledged.

\section{References}

[1] H. Song, K. Nam, "Dual current control scheme for PWM converter under unbalanced input voltage conditions," IEEE Transactions on IE, vol. 46, No. 5, October 1999.

[2] G. Saccomando, J. Svensson, "Transient operation of grid-connected voltage source converter under unbalanced voltage conditions," Industry applications conference, 2001. 36th IAS annual meeting. Conference record of the 2001 IEEE, vol.4, 30th September - 4th October 2001. Pages 2419 - 2424.

[3] Y. Suh, V. Tijeras, T. Lipo, "A nonlinear control of the instantaneous power in dq synchronous frame for PWM AC/DC converter under generalized unbalanced operating conditions," Conference record of the industry applications conference, 2002. 37th IAS annual meeting, vol. 2, 13th -18 th October 2002. Pages $1189-1196$.

[4] Y. Suh, T. Lipo, "A control scheme of improved transient response for PWM AC/DC converter under generalized unbalanced operating conditions," 2004 35th annual IEEE Power electronics specialists conference.

[5] F. Magueed, A. Sanino, J. Svensson, "Transient performance of voltage source converter under unbalanced voltage dips," IEEE 35th annual power electronics specialists conference (PESC'04). Aachen, Germany. 20-25 June 2004. Pages: 1163 - 1168.

[6] B. Yin, R. Oruganti, S. K. Panda, A. K. S. Bhat, "An Output-Power-Control Strategy for a Three-Phase PWM Rectifier under Unbalanced Supply Conditions," IEEE Transactions on IE, Vol. 55, No. 5, May 2008, 2140-2151.

[7] C. H. Ng, L. Ran, J. Bumby, " Unbalanced-Grid-Fault Ride-Through Control for a Wind Turbine Invertor," IEEE Transactions on IA, Vol. 44, No. 3, May/June 2008, 845-856.

[8] S. Alepuz, S. Busquets-Monge, J. Bordonau,J. A. Martinez-Velasco, C. A. Silva, J. Ponnt, J. Rodriquez,"Control Strategies Based on Symmetrical Components for Grid-Connected Converters under Voltage Dips," IEEE Transactions on IE, Vol. 56, June 2009, 2162-2173.

[9] A. J. Ferre, O. G. Bellmunt, T. C. Green, D. E. S. Sanchez," Current Control Reference Calculation Issues for the Operation of Renewable Source Grid Interface VSCs under Unbalanced Voltage Sags," IEEE Transactions on PE, Vol. 26, No. 12, December 2011, 3744-3753.

[10] Y. F. Wang, Y. W. Li, "Grid Synchronization PLL Based on Cascaded Delayed Signal Cancellation," IEEE Transactions on PE, Vol. 26, No. 7, July 2011, 1987-1995. 